\title{
Study on Roles of Teachers in Applied Medical Colleges Under the Student-centered Idea
}

\author{
Changhai Yun a, Li Shuang ${ }^{b}$, Fu Yanran ${ }^{c}$, Liu Chunmiao ${ }^{d}$, Liu Fu ${ }^{\text {e }}$ \\ Qiqihar Medical University, Qiqihar City, Heilongjiang Province, 161006, China \\ email: ${ }^{\mathrm{a}}$ Yunch1234@163.com, ${ }^{\mathrm{b}} 97500742 @ q q . c o m,{ }^{\mathrm{c}} 957695590 @ q q . c o m,{ }^{\mathrm{d}} 29020230 @ q q . c o m,{ }^{\mathrm{e}} 9750074$ \\ 2@qq.com
}

Keywords: The student-centered idea; Applied medical college; The role of teachers

\begin{abstract}
The construction of the roles of teachers in applied medical college is an important approach to promote the reform of teaching and improve the quality of teaching. This paper mainly aimed at the present situation of teaching construction in applied medical college. Based on the student-centered idea, some of recommendations were proposed to enhance the construction of roles of teachers in applied medical colleges, which is of great significance to improve the teaching quality.
\end{abstract}

\section{Introduction}

The role of teachers in a kind of standard of behaviors, which is rooted in the idea of teachers and is shown by the idea of teachers and the education behaviors. The orientation of teacher's role based on the student-centered idea is a new requirement for teachers in applied medical colleges. In the reform of applied medical colleges, the role of orientation and innovation behavior, as important variables, have a profound influence on the evolution of education concepts and the implementation of the whole educational reform. Therefore, it is great theoretical and practical significance to explore the orientation of the role of teachers in applied medical colleges.

\section{The Reflection of Roles of Teachers in Applied Medical Colleges Under Traditional Education Idea}

John Deway first proposed to allow students to become the center of education, call for education to achieve a "Corpernican revolution", and then alternated the original "teacher-centered" idea to "student-centered" idea. The student-centered teaching is to cultivate a proactive self-growing person. In order to achieve this goal, teachers must make feasible evaluations for each stage of student growth, and then the traditional teaching evaluation can not achieve this goal. In general, the methods of student-centered idea includes the following aspects: active learning, cooperative learning and inductive teaching and learning. As an important part of social roles, the role of teachers includes the professional idea of teachers, the social expectation of teachers, the social responsibility and behavior patterns of teachers. This paper focused on the education concept and identity of teachers in applied medical colleges in related education and personnel training. The growth path of teachers in applied medical colleges is different from teachers in primary and middle schools and traditional vocational colleges. The teachers in primary and middle schools are graduated from normal colleges, who have sufficient training and transparent professional paths before their careers. Most of the higher vocational teachers come from the general colleges and universities, and some of them are from the front line of production. Although they have good professional knowledge and skills, their curriculum design, teaching methods, the purpose and value of education are uneven. Compared with above teachers, teachers in applied medical colleges are graduated from ordinary universities. Their education, teaching and research activities are based on the inheritance of academic system. 


\subsection{Technical rationality dominates the student development}

Under the guidance of technical rationality, the one-sided student development idea has been developed, which emphasizes the teaching of "work skills". Teachers who admire technical rationality regard the imparting and training of work skills as the only content of the implementation of medical education. Medical teachers who admire technical rationality do not admire the "human development", but the acquisition of skills. They equate the development of the students with the imitation and reproduction of the skills, making their students' view of development narrowed and superficial, thus forming a distorted view of the students' development. In their view, students are the consumers of working skills. They understand nothing about working skills, and their past experience is of no value and significance to skill learning.

\subsection{Knowledge based concept has shaped the role of "knowledge authority" teachers}

The development of society and human being are mutual restriction, mutual promotion and mutual transformation, and Education is the most important and effective way to transform the contradiction between the development of human beings and the development of society. Education is in a position of intermediary transformation in the contradiction between human development and social development. Therefore, there is a debate Whether there is a student centered or teacher centered in educational ideas or curriculum construction. Medical education emphasizes the cultivation of practice ability, which is based on an independent academic system. Due to the medical education emphasizes the professionalism and practicality of curriculum, curriculum construction in applied medical Colleges seems to have a natural connection with "Teacher centered" idea. Under this guidance, teachers, as the "prophets" of knowledge and skills, naturally form a top-down non equal relationship in the face of students, as the "consumers" of knowledge and skills. Under this circumstance, students are regarded as lagging behind in medical education, and lose their autonomy and opportunity to know themselves and build self-confidence under the guidance of "knowledge authority".

\subsection{The Student-oriented idea strengthens the module thinking of teachers}

The idea of student-oriented derives that teachers in medical colleges adopt an "unified" teaching mode during the teaching organization and then model their teaching methods. The teaching mode is a stable structure and activity established under the guidance of certain teaching thought or education theory. Teaching mode has certain integrity, stability and even closeness. It's not only the pursuit of efficient teaching quality, but also the growth of students to some extent. The teachers in the rigid teaching mode regard the classroom as a workshop with a production line, and then students are products of education, so that teachers can customize skills talents to adapt different positions by combining knowledge and skills. In the principle of giving priority to efficiency, teachers are the general needs of enterprises and society, and the individual needs of students is ignored in these models and even discarded, so that students can not choose their own direction of development.

\subsection{The praise of working skills leads teachers to evaluate students based on their outcomes}

The results of teachers' evaluation of students is that teachers concentrate on working skills to evaluate students. Under this kind of thinking, teachers in applied medical colleges evaluate students based on the number of mastering knowledge and skills in certain times, which leads to a negative situation. Due to the concept of evaluation based on result orientation, the acquisition of skills is regarded as the only criterion for good or bad. In the view of teaching evaluation results orientation, the all-round development of students become an essential skills and lifelong development, because there is no definite connotation and extension.

\section{Role Orientation of Teachers Based on Student Center in Applied Medical Colleges}

In order to promote the connotation development and teaching quality of medical education and realize the coordinated development of education and economic society, teachers in applied medical 
colleges should return to the origin of education essence, reexamine the concept of students and the role of teachers.

Teachers in applied medical colleges should break away from the worship of "technical rationality" and return to the basis of "human development". Teachers not only pay more attention to students' working skills and emotions, but also cultivate their skills to help them become a complete person in their careers. Under this concept, applied medical colleges should start from educating people and embodies the fundamental requirement of student development based on the all-round and sustainable development of students. The student-centered idea is no longer the authority of knowledge, but also a supporter for the sustainable development of students.

\subsection{Setting up the student-centered idea}

The student-centered idea requires the transformation from "teachers, classes and teaching materials" to "students, learning and learning process". In this process, teachers should focus on "teaching" and "learning", and are no longer the "prophets" and "authority" about the knowledge and skills. In the deconstruction of "knowledge authority", it is replaced by the equality of teachers and students, and then teachers and students are subjects to the pursuit of knowledge and skills. In such equal situations, teachers promote the dialogue and communication with students, and then their experience and personality are treated equally. At last, the teachers are liberated from the opposite of students and become the caretakers on the way of students' growth and the supporter of students’ sustainable development.

\subsection{Constructing learning community and becoming the creator of individualized and artistic teaching products}

The technical rationality equates the colleges with the production workshops of educational products. Teaching process is strictly patterned, programmed and standardized. Teachers, who adhere to the student-centered idea, do not negate the scientific teaching mode, but profoundly understand the precise and efficient education mode, which could mix the vivid teaching mode with scientific learning. The medical teachers who insist on student-centered idea should be "production workers" in the teaching mode, turn into a personalization and artistic practitioner of students, and allow each student has opportunities to choose the direction of their own developments. Through this alternation, the standardized teaching mode is regarded as an unrelated or interfering factors that might influence students' emotion, will and interest. Therefore, the applied medical colleges no longer pursue the unity and standardization, but concentrate on dialogue, nonlinearity and chaos as normal. The teaching mode of applied medical colleges are not only scientific but also the art of experiencing and understanding. Teachers respect individual difference, teach students in accordance with their aptitude, and accept and appreciate diversity in the process of education.

\subsection{Adhering to a comprehensive view of student evaluation}

The values of students are not only related to the selection of students, but also affect teachers' expectation and encouragement of students. Teachers who pay more attention to skill acquisition play quality inspectors in the evaluation of students, and they evaluate students through their employment and salary level. However, the student-centered idea demands that teachers should change from "neutral” referees to students' professional coaches. Therefore, teachers in applied medical colleges should broaden their evaluation contents under the guidance of student-centered idea, and actively incorporate students' knowledge and skills, emotions and attitudes, beliefs and values into the field of vision and scope.

\section{Summary}

To sum up, the knowledge economy is deepened, and then the industrial structure is accelerated and upgraded. Therefore, the complex labor has put forward higher requirements for the medical students. Therefore, the role orientation of teachers in applied medical colleges under the student-centered idea should focus on the education of human nature. In addition, the teachers in 
applied medical colleges should adhere to the student-centered idea, and rediscover the "edutainment" and "human nature" of the medical education as well. At last, the teachers should return to the essence of focusing on education, take the initiative to embrace the new era again, and to achieve their own overall development in helping students to develop.

\section{Funding}

Heilongjiang provincial education science planning key project "Studies on application-oriented teacher's role positioning in medical school under student centered education concept" (GB1317144)

\section{References}

[1] Wu Suping. Students-centered Vocational Education idea and the teachers' location [J]. Career Horizon, 2007, 3(10): 49-50

[2] Zhang Xiaolei, Zeng Jiwei. On Students-centered Model in English Teaching. Journal of Zhejiang Textile \& Fashion College, 2009, 8(3): 108-109.

[3] Xu Yin. Construction of Student-centered Relationship Between Teachers and Students in Higher Vocational Colleges Under the Information View. Asia Pacific Education, 2015, (26): 13-14.

[4] Hu Zhiquan. Study on the Design of Micro Class Teaching Under the Concept of Student-centered. Journal of Sichuan Vocational and Technical College, 2017, 27(2): 145-149.

[5] Fu Na, Luo Yating. Analysis of the Current Situation of Concept of Student-centered in Higher Vocational English Teaching. Read and Write Periodical, 2011, 8(1): 29-30.

[6] Yang Yuanfen, Hu Jianxiong Zhaung xinyuan. The innovation of primary level party construction in colleges and universities---The operation effectiveness and reflection of student's party affairs center. Journal of Nanchang College of Education, 2015, (2): 4-6.

[7] Liu Liping. The Role Orientation of English Teacher in Higher Vocational Education and Cultivation of Students' English Autonomous Learning Ability Under the Multimedia Teaching Mode. Scientific Consult, 2010, (16): 107-108. 